\title{
A Way of Being:
}

\section{Bringing Mindfulness into Individual Therapy}




\begin{abstract}
This paper reports a qualitative, idiographic study employing Interpretative Phenomenological Analysis to explore the experiences of therapists who have a mindfulness practice, looking at how this is brought into their individual therapeutic work. Findings focus on mindfulness, conceptualised as a way of being, which emerges as a central theme in all accounts. Three "way of being" related themes are used to illustrate therapists' experiences of mindfulness as part of their personal life and how this is brought into the therapy room both implicitly and explicitly. The application of mindfulness in therapy is discussed while drawing links with the mindfulness literature.
\end{abstract}

Keywords: Mindfulness, Meditation, Therapeutic applications, Interpretative Phenomenological Analysis, Therapeutic relationship 


\section{Introduction}

The interest in mindfulness and its clinical applications has increased exponentially over the last 20 years, leading to a considerable amount of research in the area. Far from being a new concept, the history of mindfulness spreads over the last 2500 years, being rooted in the Eastern traditions and in particular Buddhism and Buddhist philosophy, forming an integral part of its teachings. Mindfulness comes from the Pali word sati, which means awareness, attention and remembering, also understood as 'bare' attention (Engler, 1986; Nyaniponika, 1973), which can allow us to develop insight into the nature of the mind, psychological processes and reality (Nyanaponika, 1965). Mindfulness could be described as an awareness of what is happening in the present moment characterised by a non judgemental, open and accepting attitude towards everything that arises in consciousness, without trying to change it. One of the definitions of mindfulness that has been most consistently used in the literature is Kabat-Zinn's (1994), who conceptualises it as "paying attention in a particular way: on purpose, in the present moment, and non-judgementally" (p. 4). Broadening the scope of this definition, Brown and Ryan (2004) suggested that mindfulness is a quality of consciousness, "an open or receptive attention to and awareness of ongoing events and experience" (p. 245).

The above definitions have been criticised for including too many lay psychology terms and concepts, such as consciousness, which have escaped scientific scrutiny (Hayes and Shenk, 2004). Inconsistencies within the literature have also been highlighted in terms of how mindfulness is conceptualised and operationalised, as it can be seen by different authors as a technique, a psychological process or an outcome (Brown, Ryan, and Creswell, 2007; Hayes and Wilson, 2003). As mindfulness has been studied mainly as part of clinical interventions, the particular inclination of each approach has influenced the authors' take on it, highlighting some aspects over others. In the attempt to come closer to an operational definition that could be used consistently in the literature, Bishop and colleagues (2004) posited the existence of two fundamental elements of mindfulness, one related to the self-regulation of attention to present experience and the other to a particular orientation to experience characterised by openness, curiosity and acceptance. They proceeded to place each in a broader framework drawing on models of self-regulation and cognitive models of psychopathology, thus allowing for predictions to be made and empirically tested. However, this definition underplays some aspects that are emphasised in other definitions, such as the role of language and cognition (Hayes, Strosahl, and Wilson, 1999), observing and describing (Linehan, 1993b), which means that different conceptualisation of mindfulness will continue to be used (Hayes and Shenk, 2004).

An essentially experiential practice, mindfulness has so far escaped researchers' attempts to arrive at a consensus as regards its definition, operationalisation and measurement. This appears to be part of the latest trend towards its quantification to be able to identify and study the mechanisms of action through which mindfulness leads to its beneficial results (Allen, Blashki, 
and Gullone, 2006; Hayes and Plumb, 2007; Shapiro, Carlson, Astin, and Freedman, 2006; Roemer and Orsillo, 2003), a trend that is seen as questionable by some in terms of its feasibility due to the elusive nature of mindfulness (Gunuratana, 2002; Hick, 2008; Rosch, 2007).

The current interest in mindfulness is the latest and most successful attempt to integrate the Eastern spiritual tradition and the Western therapeutic tradition (e.g. Atwood and Maltin, 1990; Bogart, 1991; Perez-De-Albeniz, 2000), leading to a marriage between mindfulness and psychotherapy that has taken many forms. These can be broadly divided into mindfulness-based and mindfulness-informed therapies (Germer, 2005), the former aiming to introduce mindfulness practices while the latter being theoretically based in mindfulness without explicitly teaching it to clients. Some of the mindfulness-based therapies have been 'branded' and are becoming widely known to clinicians. The first one to be introduced was mindfulness-based stress reduction (MBSR; Kabat-Zinn, 1990), an intervention initially designed for people suffering from a wide variety of chronic and painful physical illnesses that has to date shown to be effective for a wide variety of conditions (for meta-analytic reviews see Baer, 2003; Bishop, 2002; Grossman, Niemann, Schmidt, and Wallach, 2004). This secular intervention aims to introduce participants to a variety of mindfulness practices, which can be divided essentially in formal and informal. Formal practices include sitting mindfulness meditation, mindful yoga stretches and the body scan, which consists in paying attention to the sensations present in each part of the body in turn. Informal practices aim to introduce mindfulness into everyday life by mindfully carrying out activities such as walking, eating and showering. MBSR has been taken as the foundation for the development of a number of other mindfulness-based therapies such as mindfulness-based cognitive therapy (MBCT; Segal, Williams and Teasdale, 2002) and mindfulness-based eating awareness training (MB-EAT; Kristeller and Hallett, 1999). Other therapies that integrate mindfulness more or less explicitly are dialectical behaviour therapy (DBT; Linehan, 1993a) and acceptance and commitment therapy (ACT; Hayes et al., 1999). Most of these interventions are delivered in a group setting and rely on a more or less structured and manualised approach, grounded in the cognitive tradition.

However, mindfulness has reached beyond cognitive therapy to include both psychoanalytical and humanistic approaches, which have claimed affinities with its practice and Buddhism more generally (e.g. Epstein, 1995; Mace, 2007; Magid, 2002; Safran, 2003), leading mindfulness to be proposed as a common factor across all kinds of therapies (Cigolla, 2009; Martin, 1997). This is the case not only in terms of theoretical similarities, but also in terms of what mindfulness can bring to the therapeutic relationship (Bien, 2006; Fulton, 2005; Gehart and McCollum, 2008; Surrey 2005), which has been recognised as one of the main vehicles for a positive therapeutic outcome (Duncan and Miller, 2000; Frank and Frank, 1991; Norcross, 2002).

Bien (2008) argues that mindfulness can be seen as "encompassing and underlying everything the therapist does" (p. 42). Qualities such as empathy, understanding, warmth and 
acceptance have been identified by clients as some of the most important characteristics of the relationship (Lambert and Barley, 2002). These have been traditionally linked with mindfulness practice in the meditation literature (e.g. Gyatso, 2001; Wallace, 2005) and many authors have suggested that these are first of all directed towards one's own experience during mindfulness practice, which then allows therapists to embody that in therapy as an attitude towards clients' experience (Bruce, Manber, Shapiro, and Costantino, 2010; Crane and Elias, 2006; Shapiro and Izett, 2008). For instance, mindfulness can increase therapists' willingness to stay with clients' difficult feelings as they become increasingly able to tolerate their own affect during their meditation practice (Fulton, 2005). The way therapists pay attention to their clients can also be influenced by mindfulness practice as it is thought to strengthen concentration and sharpen awareness of what is happening (Fulton, 2003; Morgan and Morgan, 2005), both intrapersonally and interpersonally.

There is now some empirical evidence that substantiate these claims as mindfulness practice has been found to foster empathy (Sweet and Johnson, 1990) and sustained attention (Valentine and Sweet, 1999). Further, a growing number of studies are looking into the beneficial effects of mindfulness and mindfulness-based interventions for a number of populations, both clinical and non-clinical (e.g. Brown and Ryan, 2003; Shapiro, Oman, Thorensen, Plante, and Flinders, 2010). However, most of these studies rely on self-report measures of mindfulness, which have been questioned in terms of their validity (Mace, 2007; Rosch, 2007) as there is considerable variation amongst the scales, which range from one to five factors.

As these difficulties could be seen as stemming from the experiential nature of mindfulness, it is believed that qualitative methods need to be prioritised within the area with the purpose of exploring the construct further and in light of the above mentioned difficulties presented by attempts to operationalise mindfulness. Qualitative research methods are said to provide a viable alternative for the study of complex phenomena as they allow for the exploration of the unique experience of individuals (Mason, 2002). This may in turn inform further quantitative research, clarifying existing inconsistencies in its conceptualisation.

A quick overview of the literature reveals that a few qualitative studies have already been carried out in the area and have looked at the experience of being part of mindfulness-based interventions for trainee therapists (Schure, Christopher, and Christopher, 2008), clients diagnosed with depression (Mason and Hargreaves, 2001), and a mixed group of inpatients on an acute mental health unit (York, 2007). Mace (2006) run a focus group looking at participants' understanding of mindfulness and its benefits and analysed the data using both thematic analysis and grounded theory (Strauss and Corbin, 1990). However, little is known about how mindfulness can be used in one-to-one therapy, which is one of the areas this research aims to explore. 
To this purpose the research asks about the experiences of therapists who practice mindfulness and bring it into their individual therapeutic work, inquiring into their understanding of the concept and its role in different domains of their lives both within and outside the therapy room. The research question has been kept broad to be consistent with qualitative methodology so that new insights can originate from the data rather than being imposed a priori by the researcher (Maxwell, 2005). The method of data analysis chosen was Interpretative Phenomenological Analysis (IPA; Smith, 1996; Smith, Jarman, and Osborn, 1999) which is suited to capture the subtleties of an experiential concept like mindfulness as the researcher encourages participants to provide a rich description of their experience.

\section{Method}

\section{The Therapists}

Six qualified therapists registered with either the BACP, UKCP or BPS were recruited through personal contacts of the first author and by e-mailing therapists expressing an interest in mindfulness on their website. The age of the participants, two males and four females, ranged from 29 to 55 with a mean age of 43 years. Therapists had all adopted the practice of mindfulness in their personal lives either formally or informally for 4 to 20 years. They had also indicated that they were integrating the principles of mindfulness into their therapeutic practice. Attempts have been made to provide a variety of perspectives within mindfulness such as whether participants were from a Buddhist background or not and the nature of the integration of mindfulness in the therapy (i.e. using mindfulness-based therapies vs developing one's own way of integrating mindfulness in the therapy vs training in Buddhist psychotherapy). Therapist had been working for an average of 9 years, ranging from 3 to 20 years of experience postqualification. Three participants described their theoretical approach as integrative, two as humanistic and one as person-centred. All names used in the results section are pseudonyms to protect confidentiality and other details that could reveal their identity were excluded from the transcripts.

\section{Procedure}

As this research was concerned with individual's experiences, a methodological approach was required that enabled the complexity and diversity of individual accounts to be retained. After obtaining informed consent from participants, semi-structured interviews were carried out to obtain information following the principles outlined by Seidman (2006). These were recorded 
and subsequently transcribed verbatim. The interview schedule was structured in such a way that it allowed participants to talk about their understanding of mindfulness, their personal experiences in relation to mindfulness and its practice and how mindfulness was integrated into their therapeutic practice (see appendix A).

\section{Analysis}

The method of analysis chosen for the transcribed interviews, Interpretative Phenomenological Analysis (IPA; Smith, 1996), was consonant with the aims of the research, exploring individual participant's perspectives of mindfulness and its applications in a therapeutic context. This method is phenomenological in nature as it aims to capture the essence of participants' experience. This involves a double hermeneutic (Smith and Osborn, 2003) as the researcher is trying to make sense of participants' attempt to make sense of their own experience, thus involving an interpretative element for both parties involved. The meanings that individuals ascribe to their experiences cannot be directly accessed by the researcher and are only available through a process of interpretation.

The first stage of the analysis involved reading the transcripts several times while making notes, which included descriptive comments, language-related comments and preliminary interpretations (Smith, Flowers and Larkin, 2009). The following stage of the analytical process led to a refinement of the initial annotations into emergent themes while keeping a close check on the data. Each interview was analysed in its own right by 'bracketing off' (Giorgi and Giorgi, 2003) existing ideas and assumptions developed through analysis as well as those borne from the personal experience and theoretical knowledge of the first author. Themes were then organized into a number of master-themes for each interview, which were arranged in a table. These were then compared to look for commonalities across interviews, keeping an open attitude towards each interview, thus allowing for new ideas and themes to emerge whilst trying to find a balance between similarities and differences. This also required to constantly shift between the interview as a whole and the details within each interview, a process known as hermeneutic circle, which entails that the parts can only be understood in the context of the whole and vice versa. The process continued until a final list of master-themes was produced, which captured participants' experiences and allowed the researchers to answer the research question.

At this point, it is necessary to add that Yardley's (2000) overlapping criteria of sensitivity to context, commitment and rigour, and transparency and coherence were followed throughout the research to enhance its quality and allow for evaluation. The criteria were met by carrying out a thorough literature review to identify gaps in the literature (Cigolla, 2009) and by following the methodology described by Smith et al. (2009) closely, in particular as regards interviewing and data analysis. In order to make the data collection and analysis process as 
transparent as possible, a detailed description of it was provided in the above sections and hard copies of analysed transcripts and tables of themes are available, providing a 'paper trail' that has been followed by the second author as suggested by Yin (1989). In addition, in the results section the researcher's interpretations are illustrated with quotes from the transcript to ground them within participants' experiences, representing all participants equally and highlighting both similarities and differences across accounts. As regards the criteria of impact and importance (Yardley, 2000), the discussion provides links between data, existing literature and applications for therapeutic practice.

\section{Results}

While the analysis revealed a number of important themes, one primary, major theme emerged, that of mindfulness as a "way of being". The analysis below uses the therapists' words to illustrate the understandings of mindfulness and experiences of therapists incorporating mindfulness into their practices. Within these quotes, brackets with ellipsis points (...) represent omitted material, while ellipsis points on their own represent a pause in the flow of participants' speech.

\section{Mindfulness as a Way of Being}

The experience of practicing mindfulness and bringing it into therapeutic practice was described by therapists as a "way of being", a master-theme that was common to all participants' accounts. Julia described it as:

"I think of mindfulness as a way of being, ehm, as... I guess an attitude of relationship towards one's experience of openness, of acceptance, of being non-judgemental, of embracing, an embracing presence of moment-to-moment experience and that includes embracing the changing nature of that"

Very similar definitions of mindfulness were offered by the other participants, highlighting the development of a particular attitude towards present-moment experience characterised by a nonjudgemental awareness.

However, whilst viewing mindfulness as a way of being, all participants described their experiences of mindfulness in different domains captured by the following subthemes: a way of being in personal life, a way of being in therapy, and encouraging a way of being in others.

A way of being in personal life. 
Before being incorporated into therapeutic work, mindfulness was described by participants as part of their personal life, highlighting the experiences that led them towards it. For some the journey started in childhood within the family environment, while for others it started later, often through other people's suggestions and other experiences such as yoga. However, there was a sense that most participants were looking for something, although its nature was unclear, as John pointed out: "I was looking for something but I didn't know".

This search appeared to have a spiritual quality to it, which was found in mindfulness, something that "resonated with me at a very deep level" (Rebecca). Most participants had an experience of mindfulness within a Buddhist context, encountering Insight or Vipassana meditation, which are based on mindfulness of breathing as their main practice. However also Kate, who did not come from a Buddhist background, spoke about her experience of mindfulness as: "tapping into a secure base, a kind of coming home to something (....) a spaciousness, but also a solidity, a groundedness".

Buddhist philosophy was another aspect that drew most participants towards mindfulness. Aspects of this philosophy and some of the values implicit in Buddhism seemed to have been incorporated into participants' belief system, informing how they made sense of their lives and the world around them, as it is evident in John's experience:

"I try to live in that way and this comes through in my own life and this is also reflected in the work I do as well, and with others (...) being more mindful, compassionate with oneself, compassionate with others, focusing on the interconnectedness of everything"

Beliefs in the interconnectedness of all beings and compassion seemed to be central in many accounts, perhaps providing the basis for a belief that it is possible to influence each other, something that can be done in the therapy, as the next theme illustrates.

Participants highlighted the experiential nature of mindfulness and the necessity to practice it to understand it, stressing the importance of formal practice such as sitting meditation, although finding time for it was seen as a challenge by many. Informal practices were felt to be more easily integrated in the everyday routine and the necessity to find some time to be mindful was emphasised in all accounts:

'I'm not really religious about it and there are days when it doesn't happen, but that's the intention, to have a daily practice, at least checking. I suppose a stillness practice you might call it, just making time to have some stillness in my day" (Chris)

Practicing mindfulness regularly over a period of time made it easier to be mindful and connect with the experience, as Sarah explained: "you just develop more of an internal alarm system it's like a habit that you have to develop, you have to practice it". 
Encountering mindfulness appears to have had a profound effect on participants' identities, becoming an integral part of their sense of self. For Kate it had become such an important part of her identity that it was compared to her ethnic origins: "the more I do it and become more and more aware of mindfulness you can't, it's part of who you are, you know, it's like you are Italian and I'm (nationality)". All participants spoke about how mindfulness had helped them to develop a different relationship to themselves and their experience, "a wonderful way of being" (John), which entailed a shift from a usual way of operating in the world, a "waking up to the fullness of the experience" (Sarah). The beneficial effects of mindfulness practice may help explaining why participants have persevered in their practice. Turning the attention towards present experience allowed several participants to get in touch with their body and connect with their felt experience, "a real sense of being more embodied, embodied in the self, embodied in the world" (Kate).

Julia's experience is also telling in terms of how mindfulness guided her way of relating to her own internal experience:

"it just enthuses every moment of my life from that point of view, whenever I am having sort of feelings and emotions and noticing immediately how I'm pushing them away or resisting them, and try to breath with the resistance and then come back to embrace what's there, and trying to let go of the rumination and go back to the body"

A sense of 'letting go' was reported by many participants, who appeared to be able to disidentify from the contents of their minds, allowing them to become more aware of conditioned patterns and automatic responses. Rebecca also referred to a "loosening of the story", which is related to a loss of attachment to a fixed personal narrative and sense of self to allow for fluidity and flexibility. However, mindfulness did not necessarily provide only positive experiences to its practitioners. Being in the present can be challenging and uncomfortable, as it may entail staying with difficult feelings and even uncomfortable insights, as Kate's explained: "it's not easy, it's not the easy option. And even if you do do the practice it's not always oh, that was a nice meditation, there are times when it's very challenging".

\section{A way of being in therapy.}

As well as in personal life, mindfulness was also seen as a way of being in professional life, a theme that encapsulates the more implicit integration of mindfulness in the therapy, looking at how participants' identity as a mindfulness practitioner is intertwined with their professional identity in terms of what they bring to the therapeutic relationship.

\section{Overlap of personal and professional}


Separating personal and professional identity appeared like a difficult endeavour, as the therapist is the main 'tool' through which therapy takes place. Kate described mindfulness as "so integrated into who I am as a person and who I am as a person is so much of a power of the therapist".

Mindfulness appears to have found its place into the therapeutic practice of participants quite naturally over time, a process that was generally felt to be in continuous movement, a characteristic that is in line with what mindfulness is, the observing of the unfolding nature of experience, which could include one's own therapeutic practice.

"I just trust the process, because I have been doing it for such a long time and I am so....comfortable and I just know, I know that it comes out and it's such a natural experience" (John)

For some, training provided an arena where mindfulness could be thought about in terms of therapeutic practice, either as an integral part of the training or as something that was aligned with the chosen therapeutic model, in particular humanistic therapy: "Acceptance and not judging and, you know, the unconditional aspect of person-centred it obviously kind of really fits in there for me (...) the kind of values of how to be in relationship" (Sarah). There seemed to be an attempt to bring together the personal and the professional into a coherent whole, with mindfulness providing a common thread between different domains by allowing sharing something that had personally been found so powerful.

\section{Qualities brought to the relationship}

Mindfulness practice also appeared to impact on the professional identity of the therapists in terms of what they bring to the therapeutic relationship, although they tended to emphasise different aspects. Three participants spoke about how mindfulness practice can influence how attention is paid in therapy, as Kate suggested:

“you just notice what's emerging (...) and I think that quite often happens in therapy (...) like in those meditations, you know, it all comes, it develops, it passes away and another one develops and emerges, and it's the same in conversations"

The role played by mindfulness in enhancing awareness was also discussed by many participants, both in terms of self-awareness and the ability to follow the relational process unfolding between therapist and client:

"It's kind of noticing and being aware of it so that in the awareness of it I'm not acting out from that place, I'm aware it has become part of my field of experience, oh, all right, right now I'm feeling attacked and as part of that I want to defend myself and in that I notice the sensation of tightness in my chest or I notice the sensations.... so it's the ability 
to know kind of what's happening moment to moment in myself and also with the client" (Rebecca)

Mindfulness appeared to facilitate awareness of one's reaction to the client and urges to react in ways that may be counter therapeutic, allowing the therapist to disengage from this and choose a more appropriate course of action. This highlights an openness towards the dynamics played out in the relationship and a willingness to explore them with clients in a non-defensive way. Linked to this is the capacity to tolerate the uncertainty that is inherent in the therapeutic endeavour, as Rebecca described: "you become more comfortable with is hanging out into the not knowing and just be enquiring into the not knowing and, you know, wondering what's going on'. Therapists' experiences of having had to face difficult feelings during their mindfulness practice can also enhance their ability to be with clients' distress, as Julia explained:

"my own experience of doing that and coming out the other side has given me that, that strength and that faith, that if I get clients to be aware of their experience they won't collapse (....) It has probably given me a greater ability to tolerate clients' distress, I suppose, not get so scared of it or think that I have to take it all away"

Most participants linked these qualities with their mindfulness practice, which was seen as having a critical impact on the quality of the therapeutic relationship in terms of "depth, presence and immediacy" (Chris), creating "a relational field in a way and I think that people know it, people experience it" (Rebecca). Mindfulness also encouraged "working at relational depth, that's kind of feeling what a client is feeling but that is, is quite detached at the same time" (Chris). It is the attitude that mindfulness fosters that allowed therapists to relate to their clients in a more meaningful way, as Sarah said: "valuing a mindfulness position in terms of being with rather than doing something about informs how I am as a therapist and how I encounter my clients in quite a fundamental way".

There was a hope that this way of relating towards experience could be "internalised as a way of being to themselves" (Sarah) in terms of:

"taking a kind of curiosity and a willingness, a willing curiosity to simply be with the intensity of experience as it is in that moment (...) I believe in kind of modelling that in my attitude to the client as they go through their stuff, that I'm modelling that as a possibility for them as well" (Chris)

"Really embodying being a mindfulness practitioner" (Kate) was therefore seen as a powerful way of working with clients that in its own right can influence the therapeutic process.

\section{Encouraging a way of being in others.}


As well as implicitly modelling a different way of being, therapists also integrated mindfulness more explicitly by encouraging a mindful attitude in the sessions. A point made by all participants is that mindfulness needs to be introduced gently, taking into account the clients' process and their readiness to engage with it. As Julia said: "I would let it unfold from what the client is bringing, their difficulties and the formulation we build together". For instance, mindfulness was seen by many as an ideal way of working with anxiety, while more caution is needed around trauma as "some clients may be so traumatised that they may find their bodies a very unsafe place to be" (Rebecca), making it essential to be mindful of individual differences.

Integrating mindfulness explicitly also gave rise to some thoughts about how mindfulness can be presented to clients. Most felt that the Buddhist origins of mindfulness had to be kept separate from therapy and that mindfulness should be integrated as a secular intervention to make it more accessible to people, unless clients showed an interest in Buddhism themselves, as Chris explained:

"If a client expressed any interest then I'd certainly mention it, I may acknowledge its, original roots in early Buddhist meditation practices but if I did I would then quickly talk about how it has been secularised for contemporary use in a kind of psychological, clinical application"

Despite generally not talking about it as a Buddhist practice, some participants highlighted the dangers of separating the two as something important may be lost, a concern shared by Sarah: "I think there is a danger there, I think there is a danger of somehow, kind of reductionism".

With this in mind, all therapists spoke about how they tended to move the focus of the session to the here and now, encouraging clients to connect with their experience as it unfolded moment-by-moment so that they could "become more aware of being in the present and being aware and open to experience experiences in the present moment" (Chris). This was done explicitly by most therapists, often through the means of the breath. While some encouraged clients to practice mindfulness of breathing in the sessions or sometimes even in everyday life, for others it was more of a general present-centred stance that was promoted, hoping it can increase awareness. The breath was often seen as an empowering and containing tool as:

"it is very powerful for people when they feel out of control, when their thoughts, emotions [are out of control] they realise that in this moment they can actually, they can gain a sense of groundedness by focusing on the breath" (John)

From a narrow focus on the breath the attention is then expanded to a wider range of experiences: "just come back to your breathing, just notice your breathing and that brings you right into the moment and then it's kind of what sounds, what sensations, what am I feeling" (Sarah). 
Encouraging clients to become aware of physical sensations and feelings experienced in their body was seen as fundamental and as a great way of overcoming impasses, the body seen as possessing an inherent wisdom, as "the body knows what's true" (John). Including a bodily felt sense of a feeling or experience was seen by some as complementing talking about a problem, while for others it was where the real work took place as it opened up a lot more possibilities. As Rebecca explained:

"talking about something is on one level, but then there is the self experience of something, so what tells you that you feel lonely and... somebody may say I feel a tightness here or feel pain in my heart and then there may be an inquiry into: 'so, is that familiar, is that feeling a familiar feeling?' And that may then bring past experiences"

This also shows that staying in the here and now does not mean that the past and future are ignored, as they still came into therapy through present experience if relevant. By focusing the attention on what is happening in the body it is possible to watch the process as it unfolds, thus helping to promote awareness and disengage from habitual ways of functioning and conditioned patterns of thoughts and behaviours, as Julia explained:

"I'm inviting them to disengage from the story in their head about it, I don't, oh, no, why am I doing this, or that means that I'm a failure or that means that bla, bla, bla. It's just stop the bla, bla, bla, and just come back to the physical sensations"”

The present-centred focus was also seen as characterised by some qualities such as nonjudgemental acceptance, openness and curiosity. In particular, acceptance seemed to be what participants found to be a most powerful way of working, as it entails going against some of the natural tendencies of human beings, avoiding and resisting painful experiences so that "instead of investing all the energy in fighting you can unpack it and see what it's about and where it takes you" (Kate). This can be seen as quite a revolutionary way of working by clients and Chris talked about the need to introduce the concept gently:

"you could put off a lot of people if you, if you said that you weren't on the same agenda of symptom reduction as them, most clients, most clients come to you wanting to feel better whereas in the mindfulness traditions you could almost say that the agenda is getting better at feeling, whatever the feeling is, but getting better at feeling. And this is not an easy thing to hear"

Acceptance, far from being passive resignation, paradoxically allows a shift to happen. For instance:

"they may then notice the resistance, oh, my god, I don't wanna feel this! Ok, accept that as well, where is that, where is the resistance in the body and so they'll go into that and what they seem to report when they do that is that, certainly what they are feeling 
becomes more tolerable, it moves, it changes, it doesn't just stay there, or in the same intensity" (Julia)

However, this "is not always easy" (John), in particular when clients fear to become overwhelmed by their difficult feelings. Bringing an attitude of compassion and open curiosity towards the experience can help to counteract that. Working towards developing a compassionate attitude towards oneself was also seen as an important aspect of therapy as it addressed clients' tendency towards self-criticism. For instance, Sarah talked about it quite explicitly to clients:

"you are giving yourself a really hard time and actually, you know, how can you kind of befriend that part of you that is making these kind of choices (...) actually finding that kind of non-judgemental compassionate way of being"

In addition to bringing awareness to the present and adopting a non-judgemental stance, some therapists also used specific techniques taken from mindfulness-based therapies such as ACT or MBCT. It is quite interesting to look at John's experience in the interview while talking about his way of integrating mindfulness compared with practitioners who use mindfulnessbased therapies:

"I never worked with...like a mindfulness practitioners in the sense of doing one of those mindfulness-based therapies like ACT or, or... having those experiences. (...) and it's probably more advanced, way more advanced than me but then again you can't (laughs) compare myself with those people, you only ever have a mindfulness moment, if I am mindful in this moment I'm either mindful or I'm not"

John appeared to believe that his way of integrating mindfulness was somewhat inferior to someone who has trained to integrate mindfulness in therapy. However, when he laughed he seemed to realise that actually mindfulness is moment-by-moment awareness, there is no sophisticated technique behind it, which seems to capture well the idea that mindfulness is a way of being, not doing within the therapy.

\section{Discussion}

Therapists' understanding of mindfulness, its practice and incorporation into individual therapy was a concern of this research. The findings illustrate a common understanding of mindfulness as a way of being characterised by a particular attitude towards experience that permeated both the personal and the professional life of participants. This is brought into therapy both implicitly by modelling and embodying it in the therapeutic relationship, and more explicitly by encouraging a present-centred and accepting attitude through different means. 
This research presents definitions of mindfulness used by participants, which appear consistent with those used in the literature by Kabat-Zinn (2003) and Bishop and colleagues (2004). However, by exploring mindfulness meaning in more depth, the theme "way of being" was developed, which indicates that mindfulness was described as an approach to life deeply embedded into participants' sense of self and worldview. Understanding mindfulness as a way of being is not a new concept in the literature (e.g. Hick, 2008; Kabat-Zinn, 1990; Roberts, 2009; Schuster, 1979). Often mindfulness has been described as shifting from "doing mode" to "being mode" (e.g. Bien, 2006), allowing ourselves to experience the richness of the present moment rather than focusing on past or future. Expanding this, a mindfulness practitioner can be seen as striving towards a way of being-in-the-world, a way of responding to the changing nature of present-centred experience by bringing curiosity, acceptance and compassion to it.

This way of being was evident in all of the sub-themes, in particular in the first one, where mindfulness was described as an important part of therapists' private lives, something that resonated with them and that, with time and practice, was integrated within their sense of identity. Paradoxically, mindfulness was also seen as something that allowed participants to disengage from their personal narratives to foster a sense of fluidity, an aspect has been discussed in the meditation literature as 'anatta', or no-self (e.g. Epstein, 2007). The journey into mindfulness also was described as having a spiritual component that led to the incorporation of values and beliefs that contributed to the development of a particular outlook on life and experience. The process then highlights the personal investment and commitment to this way of being made by participants.

Being a mindfulness practitioner also influenced the way therapists are in the room with clients, as indicated by the second sub-theme, a way of being in therapy. In participants' accounts, mindfulness appears to promote the natural development and application of listening skills, possibly a result of turning the attention towards particular aspects of the experience in mindfulness practice (Fulton, 2003; Morgan and Morgan, 2005). This is also reminiscent of the concept of 'evenly hovering attention' (Freud, 1912), allowing what is important to naturally come to the forefront. Awareness of both self and the relational process appears to be promoted so that therapists' likelihood of acting out is reduced and they are open to a non-defensive exploration of the client's experience. Participants also reported being more comfortable with and better able to tolerate clients' distress and not-knowing, bringing a compassionate curiosity to it. Mindfulness practice also encouraged the development of a compassionate attitude towards the self, which can then be extended towards other people. Compassion has been discussed at length in the Buddhist literature (e.g. Dalai Lama, 2001) and is now entering into mainstream psychology both as a construct that can be researched (e.g. Neff, 2003; Leary, Tate, Adams, Allen, and Hancock, 2007) and as part of recently developed interventions (Germer 2009; Gilbert, 2010). On the whole, mindfulness appears to foster an attitude akin to what Rogers (1961) calls "therapeutic presence", which subsumes his three core conditions of empathy, 
unconditional positive regard and genuineness, aspects that are themselves related to different facets of mindfulness (compassion, acceptance and openness respectively). Linked to this is relational depth (Mearns, 1996), which was mentioned by one of the therapist interviewed and is related to an attitude of compassion and empathy that pervades therapists' therapeutic stance, allowing for a deep connection with the client.

The results of the current research seem to be in line with conceptual literature suggesting that mindfulness practice can have a beneficial effect on the therapeutic process (e.g. Bien, 2006; Bruce et al., 2010; Childs, 2007; Crane and Elias, 2006; Fulton, 2005; Gehart and McCollum, 2008). However, despite subtle qualities such as acceptance, compassion, curiosity and openness have been emphasised in all accounts, they are aspects of mindfulness that have been regarded as superfluous by some researchers when attempting to operationalise and measure it. For instance, they are missing in one of the most widely used self-report measures of mindfulness, the Mindful Attention Awareness Scale (MAAS; Brown and Ryan, 2003), which may indicate that such research is missing an important aspect (Christopher, Charoensuk, Gilbert, Neary, and Pearce, 2009), although Brown and Ryan (2004) explained that the acceptance component did not seem to add to the psychometric properties of the scale.

The third subtheme, encouraging a way of being in others, encompasses the more explicit integration of mindfulness in the therapy. Participants explained how mindfulness can be fostered by encouraging clients to pay attention to different aspects of their present experience, starting from the breath and then shifting to emotions and physical sensations. To complement this, the same qualities that therapists bring to their own experience are fostered in clients, including non-judgemental acceptance, openness, curiosity and compassion. Bringing the body into therapy is one of the strengths of integrating mindfulness according to the therapists interviewed, as it emphasises another dimension of experience that clients may not immediately be aware of, thus promoting a greater integration of mind and body. The body is a somewhat neglected aspect in psychotherapy with the exceptions of certain therapeutic approaches such as body psychotherapy (Aposhyan, 2004; Corrigall, Payne, and Wilkinson, 2006); including it could open the doors to possibilities that are relatively unexplored in the field and could help explaining why mindfulness appears to be so beneficial.

In order to integrate mindfulness meaningfully into the therapy, therapists mentioned that it is essential to be attentive to the therapeutic process and their formulation of the client's difficulties as well as the factors that maintain them. In particular, two maintaining factors commonly encountered in their work with clients were discussed by participants. One of these is lack of awareness of conditioned patterns of thought and behaviour, something that all therapeutic traditions acknowledge. The awareness that mindfulness helps to foster seems linked with the ability to disengage from the contents of cognition, thereby creating a 'gap' that allows the mind to observe itself, enhancing awareness and opening up opportunities for a different response to the habitual one. This has been named "repercieving" by Shapiro and colleagues 
(2006) and proposed as the core mechanism of action of mindfulness, despite the first study to test this model did not find support for the mediating role of repercieving (Carmody, Olendski, Baer, and Lykins, 2009). Similar concepts in the literature are the 'observing self' found in psychoanalytic literature (Deikman, 1982) and cognitive defusion, which emphasises a changed relationship with unwanted experiences rather than trying to change them (Hayes et al., 1999). The other maintaining factor mentioned by participants was resisting and fighting present moment experience, particularly when unpleasant, which is consistent with findings that experiential avoidance is a common factor across different disorders (Hayes, Wilson, Gifford, Follette, and Stroshal, 1996). Its opposites, acceptance and willingness to be with experience, are two key elements of mindfulness, which have been discussed by both participants and the literature (Baer, 2003; Roemer and Orsillo, 2003). Staying with the experience, no matter how unpleasant, also teaches clients that it does not stay the same for very long, something that resonates with the concept of exposure, another of the suggested mechanisms of action of mindfulness (Kabat-Zinn, 1982; Linehan, 1993a; Segall, 2005).

Results have several implications of relevance for therapists. To start with, they suggest that mindfulness could be integrated into therapists' training curriculum to enhance their ability to be with their clients and strengthen the therapeutic relationship, an aspect that is commonly neglected as it proves to be difficult to achieve with standard teaching methods. However, how mindfulness can be integrated remains a matter of debate. Current studies have looked at the effects of MBSR, which has been found beneficial in terms of reducing psychological distress while increasing positive affect and self-compassion (Shapiro, Brown and Biegel, 2007), results that have been replicated with healthcare professionals (Shapiro, Astin, Bishop \& Cordova, 2005), and medical and premedical students (Rosenzweig, Reibel, Greeson, Brainard, and Hojat, 2003; Shapiro, Schwartz, and Bonner, 1998). More specifically, the Schure et al. (2008) qualitative study of counselling students engaged in a MBSR-based module found that mindfulness practices (meditation, yoga and qigong) led to a number of positive changes. These included a greater awareness of oneself and one's body as well as increased attentiveness and responsiveness to clients, aspects that have been highlighted in the present study. Despite showing that even short mindfulness-based interventions can yield positive effects, questions remains as to whether continued practice is necessary for these to be maintained as no study as yet used a longitudinal design. Participants' personal experiences indicate that regular mindfulness practice is essential to benefit from it, although this does not necessarily mean daily formal meditation as mindfulness can be integrated informally in everyday life. Nevertheless, participants suggested that developing a deep understanding of mindfulness is often a long and challenging journey, which means that it may need to be cultivated by trainees way beyond their clinical training and a brief mindfulness intervention embedded in it. This may also be necessary for therapist to be able to model a mindful attitude in-session. 
There is also potential for the qualities fostered by mindfulness to be of use for the selfcare of therapists (Shapiro et al, 2007; Schure et al, 2008). Being a therapist can be extremely challenging and stressful, which could lead to burn-out (e.g. Baker, 2003; Figley, 2002). The ability to return to present moment experience may help to switch off from work after a stressful day as well as bringing awareness to what could be signs of stress and impending burn-out. The qualities fostered by mindfulness practice may also enhance resilience as therapists may be better able to withstand the emotional impact of client work by offering the same compassionate and accepting attitude towards both self and clients, strong in their belief that it is possible to stay with difficult experiences and emotions until they start shifting. Some evidence is also available to suggest that mindfulness may lead to greater ability to tolerate negative affect in terms of willingness to stay with negatively valenced slides (Arch \& Craske, 2006) and greater prefrontal cortex inhibition of amygdale responses (Creswell, Way, Eisenberger, and Liebermann, 2007). This may also allow therapists not to take too much responsibility for their clients and be less likely to take things personally as they start disengaging from their self-views, which could include the need to be 'good therapists'.

As regards the limitations of the research, it only looked at therapists who practice mindfulness regularly, therefore excluding those who regard it as a technique or a set of skills that is taught to clients. It would be interesting to interview therapists who do not have a mindfulness practice despite teaching it to clients, perhaps as part of interventions such as ACT or DBT. As the research is of qualitative nature, the themes found reflect the subjectivity of the researcher and this is one of many possible interpretations of the complexities found in the therapists' accounts. Despite the research cannot be generalised to all therapists who practice mindfulness, results can be transferred to other similar contexts if deemed appropriate (Lincoln and Guba, 1985).

The present study has highlighted the central role played by mindfulness in the life of participants and how it can be seen as a way of being that encompasses both personal and professional domains, permeating the way therapists relate to themselves, their clients and their experiences both within and outside the therapeutic relationship. This has profound implications for therapeutic practice as mindfulness appears to foster awareness and other qualities that are essential for both therapists and clients so that an enriching therapeutic experience can take place. 


\section{Interview Schedule}

As part of my research into the experience of therapists who practice mindfulness and integrate it into therapy I am going to ask you a few questions. There is no right or wrong way of answering them, the only thing I am interested in is understanding your experience as much as possible. This means that I may ask you to explain something that appears obvious so that I can get a sense of what it means to you in particular. Please take time to think about what you want to say and do not feel rushed to give an answer straightaway.

Would you mind telling me what you understand by the term "mindfulness"?

Along these lines, how did you become interested in mindfulness?

Can you tell me about your mindfulness practice?

I understand that you also bring mindfulness into your therapeutic practice. Would you mind telling me how you do that?

More generally, what would you say it is the place of mindfulness in therapy?

\section{References}


Allen, N. B., Blashki, G., Gullone, E., \& Melbourne Academic Mindfulness Interest Group, Australia. (2006). Mindfulness-based psychotherapies: A review of conceptual foundations, empirical evidence and practical considerations. Australian and New Zealand Journal of Psychiatry, 40(4), 285-294.

Aposhyan, S. (2004). Body-mind psychotherapy: Principles, techniques and practical applications. New York: Norton Professional.

Arch, J. \& Craske, M. (2006). Mechanisms of mindfulness: Emotion regulation following a focused breathing induction. Behaviour Research and Therapy, 44(12), 1849-1858.

Atwood, J.D., \& Maltin, L. (1991). Putting eastern philosophies into western psychotherapies. American Journal of Psychotherapy, 3, 368-382.

Baker, E. K. (2003). Caring for Ourselves: A Therapist's Guide to Personal and Professional Well-Being. Washington, DC: American Psychological Association.

Baer, R. A. (2003). Mindfulness training as a clinical intervention: A conceptual and empirical review. Clinical Psychology: Science and Practice, 10(2), 125-143.

Bien, T. (2006). Mindful therapy: A guide for therapists and helping professionals. Boston: Wisdom Publications.

Bien, T. (2008). The four immeasurable minds: Preparing to be present in psychotherapy. In S. F. Hick \& T. Bien (Eds.), Mindfulness and the therapeutic relationship (pp. 37-54). London: The Guilford Press.

Bishop, S. R. (2002). What do we really know about mindfulness-based stress reduction? Psychosomatic Medicine, 64(1), 71-83.

Bishop, S. R., Lau, M., Shapiro, S., Carlson, L., Anderson, N. D., Carmody, J., et al. (2004). Mindfulness: A proposed operational definition. Clinical Psychology: Science and Practice, 11(3), 230-241.

Bogart, G. (1991). The use of meditation in psychotherapy: A review of the literature. American Journal of Psychotherapy, XLV, 383-413.

Brown, K. W., \& Ryan, R. M. (2003). The benefits of being present: Mindfulness and its role in psychological well-being. Journal of Personality and Social Psychology, 84(4), 822-848.

Brown, K. W. \& Ryan, R. M. (2004) Perils and promise in defining and measuring mindfulness. Clinical Psychology: Science and Practice, 11, 242-248.

Brown, K. W., Ryan, R. M., \& Creswell, J. D. (2007). Mindfulness: Theoretical foundations and evidence for its salutary effects. Psychological Inquiry, 18, 211-237.

Bruce, N. G., Manber, R., Shapiro, S. L., \& Costantino, M. J. (2010). Psychotherapists mindfulness and the psychotherapy process. Psychotherapy: Theory, Research, Practice, Training, 47, 83-97. 
Carmody, J., Olendzki, N., Baer, R.A., \& Lykins, E.L.B. (2009). An empirical study of the mechanisms of mindfulness in a mindfulness-based stress reduction program. Journal of Clinical Psychology, 65, 613-626.

Childs, D. (2007). Mindfulness and the psychology of presence. Psychology and Psychotherapy: Theory, Research and Practice, 80(3), 367-376.

Christopher, M.S., Charoensuk, S., Gilbert, B.D., Neary, T.J., \& Pearce, K.L. (2009). Mindfulness in Thailand and the United States: A case of apples versus oranges? Journal of Clinical Psychology, 65, 590-612.

Cigolla, F. (2009). The role of mindfulness in therapy: A review. Unpublished manuscript, Department of Psychology, University of Surrey, Guildford, Surrey, UK.

Corrigall, J., Payne, H., \& Wilkinson, H. (Eds.). (2006). About a body: Working with the embodied mind in psychotherapy. Hove, Uk: Routledge.

Crane, R., \& Elias, D. (2006). Being with what is: Mindfulness practice for counselors and psychotherapists. Therapy Today, 17, 31-35.

Creswell, J. D.,Way, B. M., Eisenberger, N. I., \& Lieberman, M. D. (2007). Neural correlates of dispositional mindfulness during affect labeling. Psychosomatic Medicine, 69, 560-565.

Dalai Lama (2001). An Open Heart: Practicing Compassion in Everyday Life. London: Little, Brown and Company.

Deikman, A. J. (1982). The observing self. Boston: Beacon Press.

Duncan, B., \& Miller, S. (2000). The heroic client: Doing client-centred, outcome-informed therapy. San Francisco: Jossey-Bass.

Engler, J. (1986). Therapeutic aims in psychotherapy and meditation. In K. Wilber, J. Engler, \& D.P. Brown (Eds.), Transformations of consciousness: Conventional and contemplative perspectives on development (pp. 17-51). Bosto'n: MA: Shambhala.

Epstein, M. (1995). Thoughts without a thinker: Psychotherapy from a Buddhist perspective. New York: Basic Books.

Epstein, M. (2007). Psychotherapy without the self: A Buddhist perspective. London: Yale University Press.

Figley, C. R. (2002). Compassion fatigue: Psychotherapist's chronic lack of self-care. Journal of Clinical Psychology, 58, 1433-1441.

Frank, J. D., \& Frank, J. B. (1991). Persuasion \& healing: A comparative study of psychotherapy ( $3^{\text {rd }}$ Ed.). Baltimore: John Hopkins University Press.

Freud, S. (1912). Recommendations for physicians on the psychoanalytic method of treatment. Reprinted (1953-1974) in the Standard Edition of the Complete Psychological Works of Sigmund Freud (trans. And ed. J. Strachey), vol. 12. London: Hogarth Press.

Fulton, P. R. (2003). Meditation and the therapist. Insight Journal, Vol. 21: Fall 2003. 
Fulton, P. R. (2005). Mindfulness as clinical training. In C. K. Germer, R. D. Siegel \& P. R. Fulton (Eds.), Mindfulness and psychotherapy (pp. 55-72). New York: Guilford Press.

Gehart, D., \& McCollum, E. E. (2008). Inviting therapeutic presence: A mindfulness-based approach. In S. F. Hick \& T. Bien (Eds.), Mindfulness and the therapeutic relationship (pp. 176-194). London: The Guilford Press.

Germer, C. K. (2005). Mindfulness: What is it? What does it matter? In C. K. Germer, R. D. Siegel \& P. R. Fulton (Eds.), Mindfulness and psychotherapy (pp. 3-27). New York: Guilford Press.

Germer, C. K. (2009). The Mindful Path to Self-Compassion: Freeing Yourselffrom Destructive Thoughts and Emotions. New York: Guildford.

Gilbert, P. (2010). Compassion Focused Therapy: Distinctive Features. Hove: Routledge.

Giorgi, A., \& Giorgi, B. (2003). Phenomenology. In J.A. Smith (Ed.), Qualitative Psychology: A Practical Guide to Methods (pp. 25-50). London: Sage.

Grossman, P., Niemann, L., Schmidt, S., \& Walach, H. (2004). Mindfulness-based stress reduction and health benefits: A meta-analysis. Journal of Psychosomatic Research, 57(1), 35-43.

Gunuratana, B. H. (2002). Mindfulness in Plain English. Somerville, MA: Wisdom Publications.

Gyatso, G. K. (2001). Transform your life: A blissful journey. Ulverston, UK: Tharpa Publications.

Hayes, S. T., \& Plumb, J. C. (2007). Mindfulness from the bottom-up: Providing an inductive framework for understanding mindfulness processes and their applications to human suffering. Psychological Inquiry, 18, 242-248.

Hayes, S. C., \& Shenk, C. (2004). Operationalizing mindfulness without unnecessary attachments. Clinical Psychology: Science and Practice, 11(3), 249-254.

Hayes, S. C., Strosahl, K. D., \& Wilson, K. G. (1999). Acceptance and commitment therapy: An experiential approach to behavior change. New York: Guilford Press.

Hayes, S. C., \& Wilson, K. G. (2003). Mindfulness: Method and process. Clinical Psychology: Science and Practice, 10(2), 161-165.

Hayes, S. C., Wilson, K. G., Gifford, E. V., Follette, V. M., \& Strosahl, K. (1996). Emotional avoidance and behavioral disorders: A functional dimensional approach to diagnosis and treatment. Journal of Consulting and Clinical Psychology, 64, 1152-1168.

Hick, S. F. (2008). Cultivating therapeutic relationships: The role of mindfulness. In S. F. Hick \& T. Bien (Eds.), Mindfulness and the therapeutic relationship (pp. 3-18). London: The Guilford Press. 
Kabat-Zinn, J. (1982). An outpatient program in behavioral medicine for chronic pain patients based on the practice of mindfulness meditation: Theoretical considerations and preliminary results. General Hospital Psychiatry, 4, 33-42.

Kabat-Zinn, J. (1990). Full catastrophe living: Using the wisdom of your body and mind to face stress, pain, and illness. New York: Bantam Dell.

Kabat-Zinn, J. (1994). Wherever you go there you are. New York: Hyperion.

Kabat-Zinn, J. (2003). Mindfulness-based interventions in context: Past, present, and future. Clinical Psychology: Science and Practice, 10(2), 144-156.

Kristeller, J. L. \& Hallett, C. B. (1999). An exploratory study of a meditation-based intervention for binge eating disorder. Journal of Health Psychology, 4, 357-363.

Leary, M. R., Tate, E. B., Adams, C. E., Allen, A. B., \& Hancock, J. (2007). Self-compassion and reactions to unpleasant self-relevant events: The implications of treating oneself kindly. Journal of Personality and Social Psychology, 92, 887-904.

Lincoln, Y. S., \& Guba, E. (1985). Naturalistic enquiry. Beverly Hills, CA: Sage.

Linehan, M. M. (1993a). Cognitive-behavioral treatment of borderline personality disorder. New York: Guilford Press.

Linehan, M. M. (1993b). Skills training manual for treating borderline personality disorder. New York: Guilford Press.

Mace, C. (2006). Long-term impacts of mindfulness practice on wellbeing: new findings from qualitative research. In A. Delle Fave (Ed.), Dimensions of Well-being. Research and Intervention, (pp. 455-469). Milano: Franco Angeli.

Mace, C. (2007). Mindfulness and Mental Health. London: Routledge.

Magid, B. (2002). Ordinary mind: Exploring the common ground of Zen and psychotherapy. Somerville, MA: Wisdom.

Mason, J. (2002). Qualitative researching ( $2^{\text {nd }}$ ed.). London: Sage.

Martin, J. R. (1997). Mindfulness: A proposed common factor. Journal of Psychotherapy Integration, 7(4), 291-312.

Mason, O., \& Hargreaves, I. (2001). A qualitative study of mindfulness-based cognitive therapy for depression. British Journal of Medical Psychology, 74, 197-212.

Maxwell, J. A. (2005). Qualitative research design: An interactive approach (3 ${ }^{\text {rd }} \mathrm{ed}$.). London: Sage.

Mearns, D. (1996) 'Working at relational depth with clients in person-centred therapy', Counselling, 7 (4), 306-311. 
Morgan, W. D., \& Morgan, S. T. (2005). Cultivating attention and empathy. In C. K. Germer, R. D. Siegel \& P. R. Fulton (Eds.), Mindfulness and psychotherapy (pp. 73-90). New York: Guilford Press.

Neff, K. D. (2003). Self-compassion: An alternative conceptualization of a healthy attitude towards oneself. Self and Identity, 2, 85-102.

Nyanaponika T. (1965). The Heart of Buddhist Meditation. York Beach, ME: Red Wheel. Nyaniponika (1973). The heart of Buddhist meditation. New York: Weiser Books.

Norcross, J. D. (2002). Psychotherapy relationships that work. New York: Oxford University Press.

Perez-De-Albeniz, A. (2000). Meditation: Concepts, effects and use in therapy. International Journal of Psychotherapy, 5, 49-58.

Roberts, T. (2009). The mindfulness workbook: A beginner's guide to overcoming fear and embracing compassion. Oakland, CA: New Harbinger Publications.

Roemer, L., \& Orsillo, S. M. (2003). Mindfulness: A promising intervention strategy in need of further study. Clinical Psychology: Science and Practice, 10(2), 172-178.

Rogers, C. R. (1961) On Becoming a Person: A Therapist's View of Psychotherapy, New York: Houghton Mifflin.

Rosch, E. (2007). More than mindfulness: When you have a tiger by the tail, let it eat you. Psychological Inquiry, 18, 258-264.

Rosenzweig, S., Reibel, D. K., Greeson, J. M., Brainard, G. C., \& Hojat, M. (2003). Mindfulness-based stress reduction lowers psychological distress in medical students. Teaching and Learning in Medicine, 15, 88-92.

Safran, J. D. (Ed.). (2003). Psychoanalysis and Buddhism: An unfolding dialogue. Boston: Wisdom Publications.

Schure, M. B., Christopher, J., \& Christopher, S. (2008). Mind-body medicine and the art of selfcare: Teaching mindfulness to counseling students through yoga, meditation and Qigong. Journal of Counseling and Development, 86, 47-56.

Schuster, R. (1979). Empathy and mindfulness. Journal of Humanistic Therapy, 19, 71-77.

Seidman, I. (2006). Interviewing as qualitative research: A guide for researchers in education and the social sciences ( $3^{\text {rd }}$ Ed.). London: Teachers College Press.

Segal, Z. V., Williams, J. M. G., \& Teasdale, J. D. (2002). Mindfulness-based cognitive therapy for depression: A new approach to preventing relapse. New York: Guilford Press.

Segall, S. R. (2005). Mindfulness and self-development in psychotherapy. Journal of Transpersonal Psychology, 37(2), 143-163. 
Shapiro, S. L., Astin, J. A., Bishop, S. R., \& Cordova, M. (2005). Mindfulness-based stress reduction for health care professionals: Results from a randomized trial. International Journal of Stress Management, 12, 164-176.

Shapiro, S. L., Brown, K., Biegel, G. (2007). Self-care for health care professionals: Effects of MBSR on mental well being of counseling psychology students. Training and Education in Professional Psychology, 1, 105-115.

Shapiro, S. L., Carlson, L. E., Astin, J. A., \& Freedman, B. (2006). Mechanisms of mindfulness. Journal of Clinical Psychology, 62, 373-386.

Shapiro, S. L., \& Izett, C. D. (2008). Meditation: An universal tool for cultivating empathy. In S. F. Hick \& T. Bien (Eds.), Mindfulness and the therapeutic relationship (pp. 161-175). London: The Guilford Press.

Shapiro, S. L., Oman, D., Thorensen, C. E., Plante, T. G., \& Flinders, T. (2009). Cultivating mindfulness: Effects on well-being. Journal of Clinical Psychology, 64, 840-862.

Shapiro, S. L., Schwartz, G. E. R. \& Bonner, G. (1998). The effects of mindfulness-based stress reduction on medical and pre-medical students. Journal of Behavioral Medicine, 21, 581599.

Smith, J. A. (1996). Beyond the divide between cognition and discourse: using interpretative phenomenological analysis in health psychology. Psychology and Health, 11, 261-271.

Smith, J. A., Jarman, M., \& Osborn, M. (1999). Doing interpretative phenomenological analysis. In M. Murray, \& K. Chamberlain (Eds.), Qualitative health psychology: theories \& methods (pp. 218-240). London: Sage.

Smith, J. A., Flowers, P., \& Larkin, M. (2009). Interpretive Phenomenological Analysis: Theory, Method and Research. London: Sage.

Smith, J.A., \& Osborn, M. (2003). Interpretative phenomenological analysis. In J.A. Smith (Ed.), Qualitative Psychology: A Practical Guide to Methods (pp.51-80). London: Sage.

Strauss, A., \& Corbin, J. (1990). Basics of qualitative research: Grounded theory procedure and techniques. Newbury Park, CA: Sage.

Surrey, J. L. (2005). Relational psychotherapy, relational mindfulness. In C. K. Germer, R. D. Siegel \& P. R. Fulton (Eds.), Mindfulness and psychotherapy (pp. 91-112). New York: Guilford Press.

Sweet, M., \& Johnson, C. (1990). Enhancing empathy: The interpersonal implications of a Buddhist meditation technique. Psychotherapy: Theory, Research, Practice, Training, 27(1), 19-29. 
Valentine, E., \& Sweet, P. (1999). Meditation \& attention: A comparison of the effects of concentrative and mindfulness meditation on sustained attention. Mental Health, Religion and Culture, 2(1), 59-70.

Wallace, B. A. (2005). Genuine happiness: Meditation as the path to fulfillment. Hoboken, NJ: John Wiley \& Sons.

Yardley, L. (2000). Dilemmas in qualitative health research. Psychology and Health, 15, $215-$ 228.

Yin, R. (1989). Case study research: Design and methods (2 ${ }^{\text {nd }}$ ed.). Beverly Hills: Sage.

York, M. (2007). A qualitative study into the experience of individuals involved in a mindfulness group within an acute inpatient mental health unit. Journal of Psychiatric and Mental Health Nursing, 14, 603-608. 